\title{
Peptidomic Analysis of the Brain and Corpora Cardiaca-Corpora Allata Complex in the Bombyx mori
}

\author{
Xiaoguang Liu, Xia Ning, Yan Zhang, Wenfeng Chen, Zhangwu Zhao, and Qingwen Zhang \\ Department of Entomology, College of Agriculture and Biotechnology, China Agricultural University, China \\ Correspondence should be addressed to Zhangwu Zhao, zhaozw@cau.edu.cn
}

Received 24 April 2012; Revised 24 October 2012; Accepted 24 October 2012

Academic Editor: Ayman El-Faham

Copyright $\odot 2012$ Xiaoguang Liu et al. This is an open access article distributed under the Creative Commons Attribution License, which permits unrestricted use, distribution, and reproduction in any medium, provided the original work is properly cited.

The silkworm, Bombyx mori, is an important economic insect for silk production. However, many of the mature peptides relevant to its various life stages remain unknown. Using RP-HPLC, MALDI-TOF MS, and previously identified peptides from B. mori and other insects in the transcriptome database, we created peptide profiles showing a total of 6 ion masses that could be assigned to peptides in eggs, including one previously unidentified peptide. A further 49 peptides were assigned to larval brains. 17 new mature peptides were identified in isolated masses. 39 peptides were found in pupal brains with 8 unidentified peptides. 48 were found in adult brains with 12 unidentified peptides. These new unidentified peptides showed highly significant matches in all MS analysis. These matches were then searched against the National Center for Biotechnology Information (NCBI) database to provide new annotations for these mature peptides. In total, 59 mature peptides in 19 categories were found in the brains of silkworms at the larval, pupal, and adult stages. These results demonstrate that peptidomic variation across different developmental stages can be dramatic. Moreover, the corpora cardiaca-corpora allata (CC-CA) complex was examined during the fifth larval instar. A total of 41 ion masses were assigned to peptides.

\section{Introduction}

Insect neuropeptides regulate behaviors during growth, development, metamorphosis, and many other physiological processes, acting as neurohormones and neuromodulators [1]. Many B. mori neuropeptides have been purified and their amino acid sequences have been determined. These include adipokinetic hormone $(\mathrm{AKH})$, subesophageal ganglion neuropeptides (SGNPs), corazonin, prothoracicostatic peptide (PTSP), B-myosuppressin (BMS), FMRFamide-related peptides (BRFas), and short neuropeptide F peptides (sNPFs) [2-7]. The cDNA precursors of some B. mori peptides, such as allatostatins A (AST-A), allatotropin (AT), and allatostatin C (AST-C), have been cloned [8-10]. The genome draft sequence in $B$. mori has been completed and this may facilitate the identification of new peptides in B. mori [11]. Recently, using homology searches and cDNA cloning, many new peptide genes have been annotated in this insect species, and their peptide precursor sequences have become available [12].

Neuropeptides have been broadly studied in many insect species, such as Locusta migratoria, Apis mellifera, and
Manduca sexta [16, 17]. However, most peptide studies focus on a specific developmental stage, either at larval or adult, which limits appreciation of the peptidomic variations that take place across different growth stages. The aim of the present study is to profile peptide complements in eggs and in the brains of silkworms at larval, pupal, and adult stages.

\section{Materials and Methods}

2.1. Insects. Silkworms from strain P50 (Dazao) were obtained from the Institute of Sericulture in Jiangsu province. They were reared on mulberry leaves at $26^{\circ} \mathrm{C}$ at $80 \%$ relative humidity and a $16 \mathrm{~L}: 8 \mathrm{D}$ photoperiod. For the experiments, eggs from day 3 were analyzed, and brains on day 4-5 of larvae, day 3 of pupae, and day 3 of male and female adults were separately dissected and analyzed.

2.2. Tissue Extraction and Liquid Chromatography. One hundred eggs were collected and incorporated into a sample, and three thus independent biological replicates (samples) were separately collected and analyzed. Similarly, one hundred of larval brains, one hundred of pupal brains, and one hundred 
of adult brains of B. mori, as well as one hundred pairs of the corpora cardiaca-corpora allata (CC-CA) complex from the fifth instar larvae, were dissected and incorporated into an independent sample, respectively, and three thus independent biological replicates were also collected and analyzed, respectively. All operations were performed on ice. Each sample was placed in a tube containing ice-cold extraction medium (methanol: water: acetic acid, $90: 9: 1, \mathrm{v} / \mathrm{v} / \mathrm{v}$ ), homogenized, and centrifuged at $12,000 \times \mathrm{g}$ at $4^{\circ} \mathrm{C}$ for 15 minutes. The pellet was re extracted twice. All supernatants were pooled, the organic solvent was evaporated by vacuum centrifugation, and the residue was dissolved in $0.1 \%(\mathrm{v} / \mathrm{v})$ trifluoroacetic acid (TFA).

The samples were fractionated on an Agilent 1100 HPLC system (Agilent, USA) using a ZORBAX StableBond C18 column $(4.6 \mathrm{~mm} \times 250 \mathrm{~mm}, 5 \mu \mathrm{m}, 300 \AA$; Agilent, USA). The column was first eluted with $3 \%$ acetonitrile in $0.1 \%$ trifluoroacetic acid (TFA) for 10 minutes. Then acetonitrile was increased to $21 \%$ over 10 minutes. This was followed by a linear gradient of $21-60 \%$ acetonitrile/ $0.1 \%$ TFA over 30 minutes at a flow rate of $1 \mathrm{~mL} / \mathrm{min}$. Fractions were collected manually every minute and concentrated by the vacuum desiccator (LNG-T88, Huamei Biochemical Company, P.R.China) to about $5 \mu \mathrm{L}$ for mass spectrometry analysis.

2.3. MALDI-TOF Mass Spectrometry. MALDI-TOF MS analysis was performed on an autoflex II TOF/TOF instrument (Bruker Daltonics, Germany). The matrix used in the analysis was a saturated solution of recrystallized $\alpha$-cyano-4hydroxycinnamic acid (CHCA; Bruker Daltonics) dissolved in $70 \%$ acetonitrile containing $0.1 \%(\mathrm{v} / \mathrm{v})$ TFA. Samples of $0.5 \mu \mathrm{L}$ were added to the MALDI plate, followed by $0.5 \mu \mathrm{L}$ of matrix solution. They were mixed and left to dry at room temperature. The spectra were obtained using an accelerating voltage of $19 \mathrm{KV}$ in the reflection mode with a mass range $\mathrm{m} / \mathrm{z}$ 700-3000. Laser power was adjusted to provide optimal signal-to-noise ratio. The measured monoisotopic masses $[\mathrm{M}+\mathrm{H}]^{+}$were compared to the calculated values of known or predicted peptides. Masses were calculated using Protein Prospector (University of California, San Francisco, CA, U.S.) [1]. MALDI-TOF-TOF mass spectra were acquired on an autoflex II TOF/TOF instrument (Bruker Daltonics, Germany). Ion fragmentation data were analyzed using FlexAnalysis software (version 3.0) from Bruker Daltonics. The mature peptide in $B$. mori from our MS/MS results were identified and confirmed by either previous publications $[3-6,8,12-15]$, or the EST from the NCBI database (http://www.ncbi.nlm.nih.gov/) and silkworm database (http://silkworm.genomics.org.cn/) [18], or the NeuroPred tool SignalP 3.0 (http://www.cbs.dtu.dk/services/SignalP/).

\section{Results}

3.1. Peptidomics in Different Organs and Developmental Stages of B. Mori. In this study, over 100 ion peaks were obtained by MS profiling from analysis of eggs and all postembryonic stages. The mature peptides were evaluated by comparison of measured monoisotopic masses $[\mathrm{M}+\mathrm{H}]^{+}$ against combination of bioinformatics and identified peptides in Lepidopteran insects and the predicted peptides from genome databases, such as calculated masses, score, queries matched, and sequence coverage. In total, 19 newfound and 40 previously reported mature brain peptides were identified in B. mori.

3.1.1. Peptides in Eggs. Only six peptides, $\operatorname{AKH} 1\left(\mathrm{Q}^{1}\right)$, $\mathrm{AKH} 2\left(\mathrm{Q}^{1}\right), \mathrm{AKH} 3\left(\mathrm{Q}^{1}\right)$, CAPA-PVK-2, allatostatin-5, and $\alpha$ SGNP, were detected in eggs. Of these, the new-found CAPAPVK-2 is a mature peptide (Table 1 marked with star).

3.1.2. Peptides in Larval Brains. A total of 49 sequences were assigned to peptides in larval brains with 17 of them unidentified mature peptides (Table 1 marked with star). These peptides mainly include AKHs $\left(\mathrm{AKH} 1\left(\mathrm{Q}^{1}\right)\right.$, $\mathrm{AKH} 2\left(\mathrm{Q}^{1}\right)$, and $\mathrm{AKH} 3\left(\mathrm{Q}^{1}\right)$ ), allatostatin $\mathrm{A}$ (allatostatin-1, $-2,-4,-5,-7,-8,-8\left(\mathrm{Q}^{1}\right)$ ), bommo-AT, bommoAST-C (AST, $\left.\operatorname{AST}\left(\mathrm{Q}^{1}\right)\right), \mathrm{BRFa}(\mathrm{BRFa}-1,-2,-3,-4)$, BMS (BMS, BMS $\left(\mathrm{Q}^{1}\right)$ ), CAPA/CAP2b (CAPA-PVK-1, CAPA-PVK-2, CAPA-PK, CAPA-PVK- $\left.2\left(\mathrm{Q}^{1}\right)\right)$, CCAP, corazonin (corazonin $\left(\mathrm{Q}^{1}\right)$ ), diapause hormone $(\mathrm{DH})$, leucokinin (leucokinin-2, -3), the mature peptides of the NPLP-1 precursor (AYLamide, LLHamide, NSYamide, SAMamide, and YRMamide), orcokinin (orcokinin-3, -4), PTST (PTST-3, -5, -6), SGNP ( $\alpha$-SGNP, $\beta$-SGNP, $\gamma$-SGNP), sNPF (sNPF- $1,-2,-3$ ), SIFamide, sulfakinin, and tachykinin (tachykinin-3, -4, 5, and -6), in which CAPA-PVK-1, CAPA-PVK-2, CAPA-PK, CAPA-PVK-2 $\left(\mathrm{Q}^{1}\right)$, leucokinin-2, -3, AYLamide, LLHamide, NSYamide, SAMamide, and YRMamide, SIFamid(SIF), sulfakinin, and tachykinin- $3,-4,-5$, and -6 are new-found mature peptides. More mature peptides were detected at this developmental stage than any other stage.

3.1.3. Peptides in Pupal Brains. 39 ion masses were assigned to peptides in pupal brains, in which 8 of them are unidentified peptides in $B$. mori (Table 1 marked with star). These peptides mainly include $\mathrm{AKHs}\left(\mathrm{AKH} 1\left(\mathrm{Q}^{1}\right)\right.$, $\mathrm{AKH} 2\left(\mathrm{Q}^{1}\right), \mathrm{AKH} 3\left(\mathrm{Q}^{1}\right)$ ), allatostatin $\mathrm{A}$ (allatostatin-3, $-4,-5$, $\left.-8,-8\left(\mathrm{Q}^{1}\right)\right)$, bommo-AT, BRFa (BRFa-1, 2, 3), B-myosuppressin (BMS, BM S $\left(\mathrm{Q}^{1}\right)$ ), CCAP, corazonin, diapause hormone $(\mathrm{DH})$, the mature peptides of the NPLP-1 precursor (LLHamide, NIAALARNGLLH-NH ${ }_{2}$; NSYamide, NIATLAKNGYLRNSGANSY-NH $\mathrm{N}_{2}$ ), Orcokinin (Orcokinin$4,-5)$, PTST (PTST- $1,-2,-3,-4,-5,-6), \operatorname{SGNP}(\alpha$-SGNP, $\beta$-SGNP, $\gamma$-SGNP), sNPF (sNPF-1, -2, -3), SIFamide, sulfakinin, and tachykinin (tachykinin-1, -3, -4). Of these, LLHamide, NSYamide, orcokinin-5, SIFamid(SIF), sulfakinin, tachykinin-1, tachykinin-3, and tachykinin-4 are newfound and unidentified mature peptides.

3.1.4. Peptides in Adult Brains. 48 ion masses were assigned to peptides in adult brains with 12 unidentified new peptides in B. mori (Table 1 marked with star). These peptides mainly include $\mathrm{AKHs}\left(\mathrm{AKH} 1\left(\mathrm{Q}^{1}\right), \mathrm{AKH} 2\left(\mathrm{Q}^{1}\right), \mathrm{AKH} 3\right.$, $\mathrm{AKH} 3\left(\mathrm{Q}^{1}\right)$ ), allatostatin A (allatostatin-3, -4, -5, -7, -8, $-8\left(\mathrm{Q}^{1}\right)$ ), Bommo-AT, BRFa (BRFa-1,-2, 3, -4), B-myosuppress-in (BMS, BMS $\left(\mathrm{Q}^{1}\right)$ ), CAPA/CAP2b (CAPAPVK-1, CAPA-PVK-2( $\left.\mathrm{Q}^{1}\right)$ ), CCAP, corazonin (corazonin, corazonin $\left.\left(\mathrm{Q}^{1}\right)\right)$, diapause hormone (DH), NPLP-1 


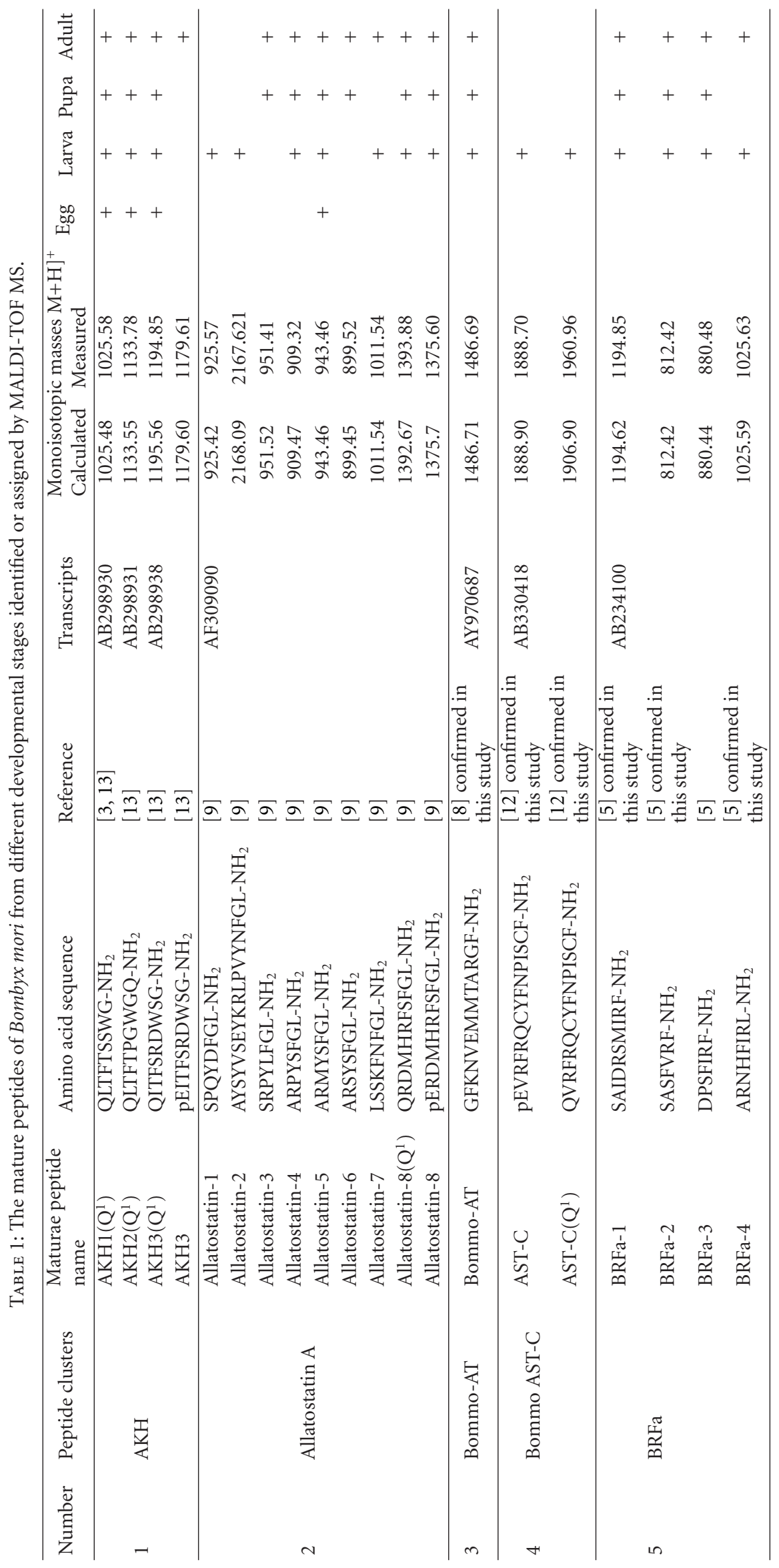




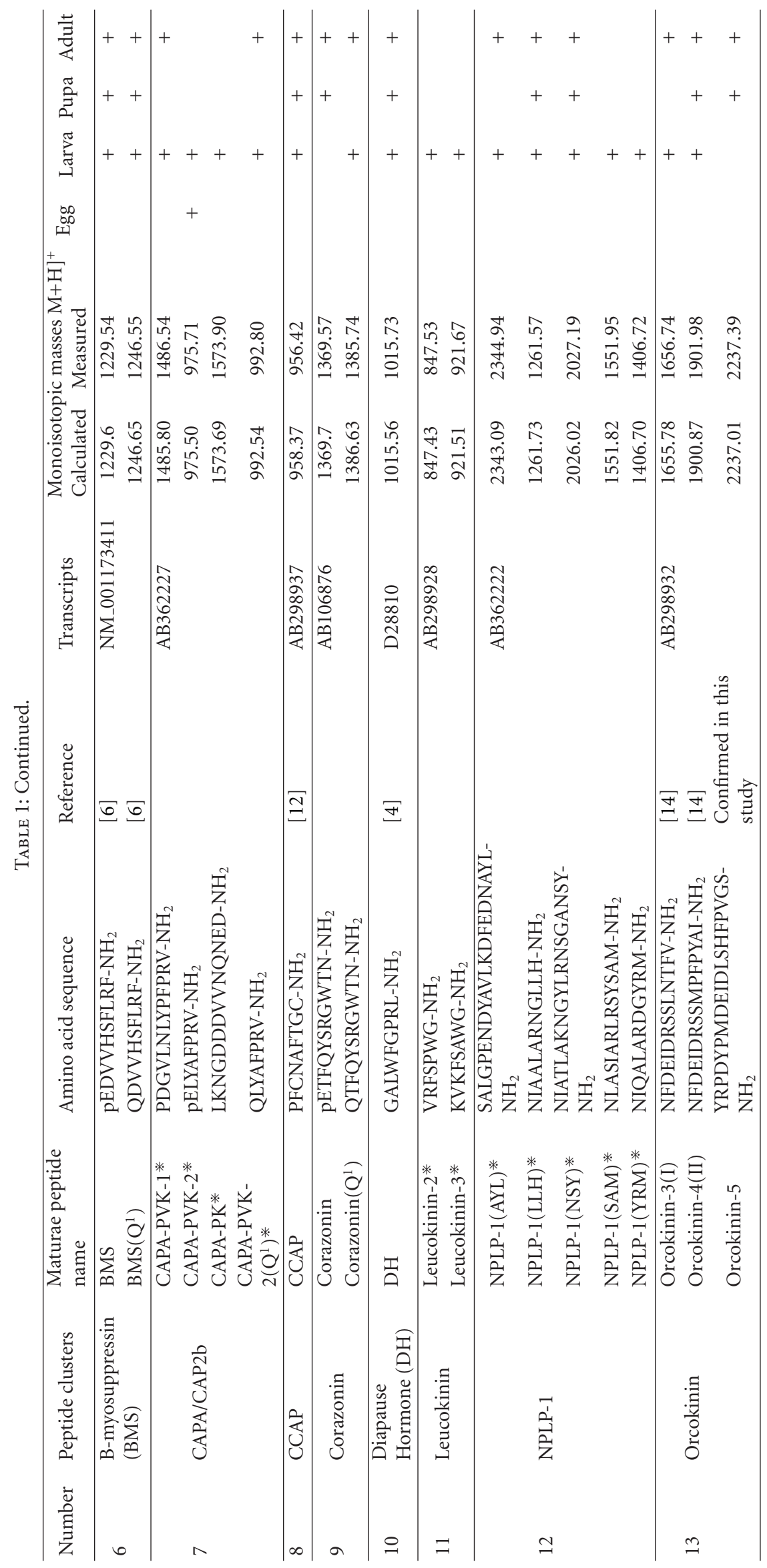




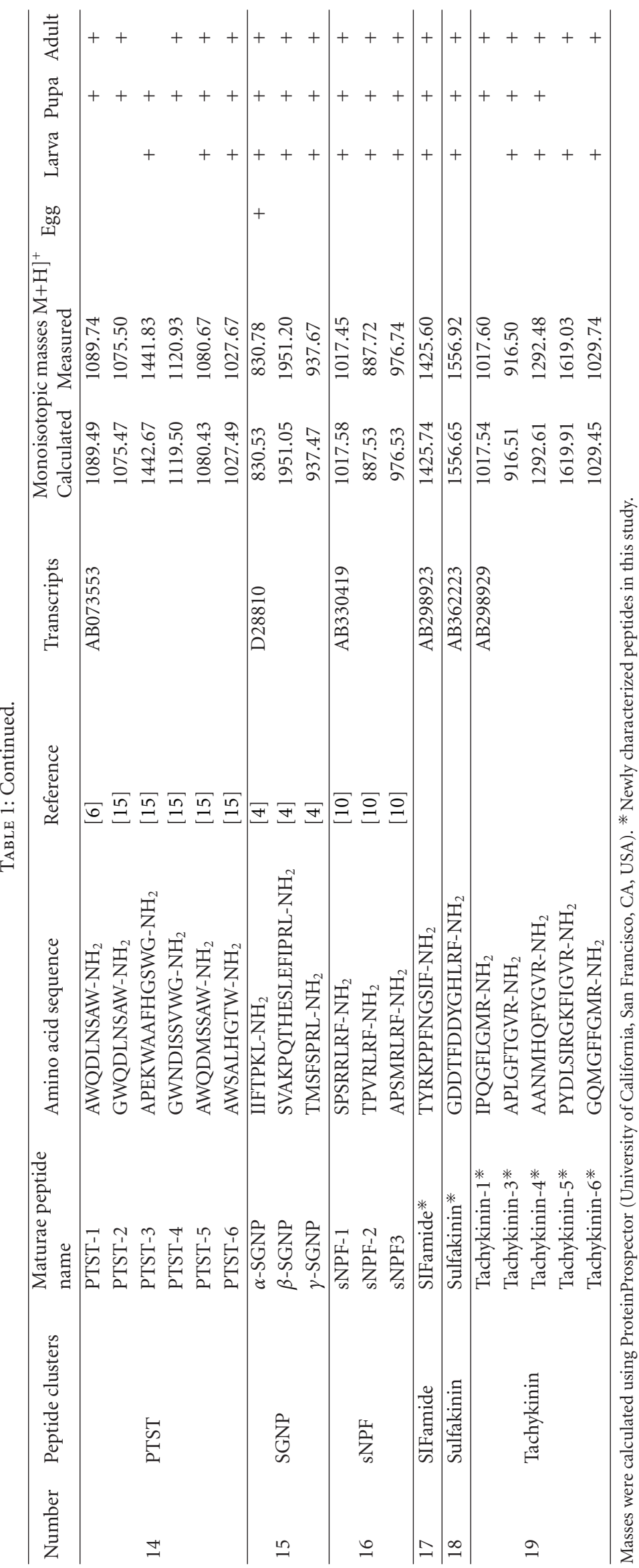




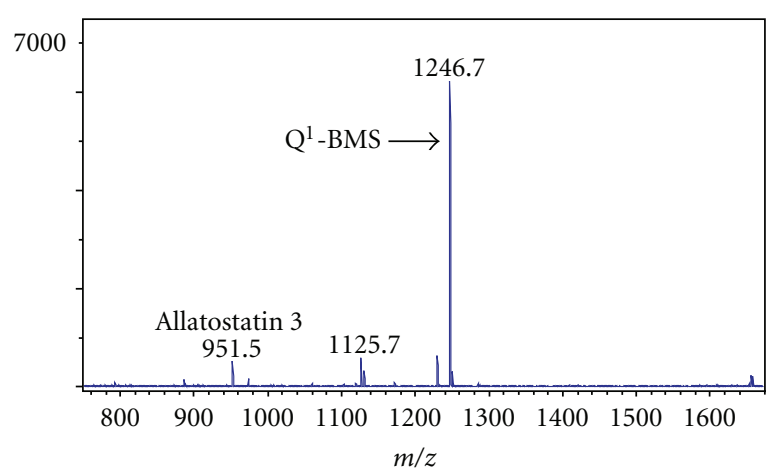

(a) MALDI-TOF-TOF fragmentation spectrum of the precursor ion at $\mathrm{m} / \mathrm{z}$ at 1246.7

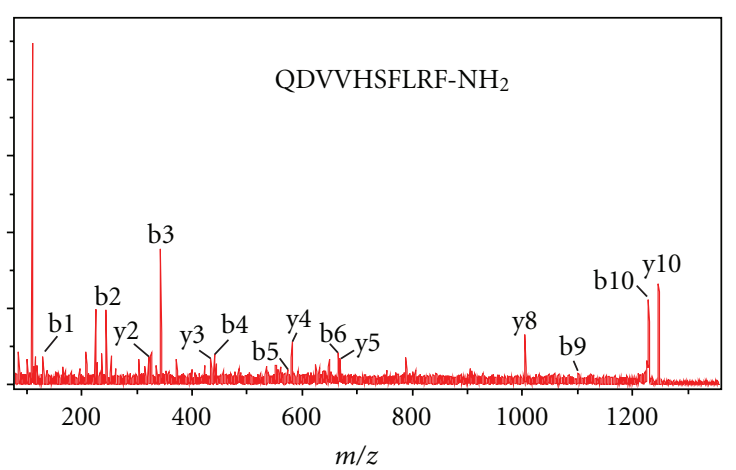

(b) A number of b-type and y-type ions are labeled

FIgURE 1: MALDI-TOF mass spectrum from separate fraction 30 of CC-CA in the fifth instar of B. mori.

(AYLamide, SALGPENDYAVLKDFEDNAYL- $\mathrm{NH}_{2} ; \quad$ LLHamide, NIAALARNGLLH-NH ${ }_{2}$, NSYamide, NIATLAKNGYLRNSGANSY-NH $\mathrm{N}_{2}$ ), Orcokinin (Orcokinin-3, -4, -5), PTST (PTST- $1,-2,-4,-5,-6)$, SGNP $(\alpha$-SGNP, $\beta$-SGNP, $\gamma$-SGNP), sNPF (sNPF-1, -2, -3), SIFamide, sulfakinin, and tachykinin (tachykinin-1, -3, -4, -5, -6). Of these, CAPA-PVK-1, CAPA-PVK-2( $\left.\mathrm{Q}^{1}\right)$, LLHamide, NSYamide, orcokinin-5, SIFamide, sulfakinin, tachykinin-1, -3, -4, -5, and -6 are unidentified mature peptides.

3.1.5. Peptides in the CC-CA Complex of 5th-Instar Larvae. CC-CA complexes sampled on days 4-5 of the fifth larval instar were analyzed for peptide profiles. A total of 41 ion peaks in these CC-CA complexes were assigned to peptides listed in Table 2. These peptides mainly include AKHs $\left(\mathrm{AKH} 1\left(\mathrm{Q}^{1}\right), \mathrm{AKH} 2\left(\mathrm{Q}^{1}\right), \mathrm{AKH} 3\left(\mathrm{Q}^{1}\right)\right)$, allatostatin A (allatostatin-2, - -3, - -4, -5, -6, -8, - $\left.8\left(\mathrm{Q}^{1}\right)\right)$, bommoAT, bommoAST-C $\left(\mathrm{AST}\left(\mathrm{Q}^{1}\right)\right)$, BRFa (BRFa-1, -2, -3, 4), B-myosuppressin (BMS, BMS $\left(\mathrm{Q}^{1}\right)$ ), CAPA/CAP2b (CAPA-PVK-1, CAPA-PVK-2, CAPA-PVK-2( $\left.\mathrm{Q}^{1}\right)$ ), CCAP, corazonin (corazonin, corazonin $\left(\mathrm{Q}^{1}\right)$ ), NPLP-1 (LLHamide, NSYamide), orcokinin (orcokinin-5), PTST (PTST-3, -5, -6), SGNP ( $\alpha$-SGNP, $\beta$-SGNP, $\gamma$-SGNP), sNPF ( $\operatorname{sNPF}-1,-2,-3)$, sulfakinin, and tachykinin (tachykinin-1, $-3,-4,-6)$. Of these, CAPA-PVK-1, CAPA-PVK-2, CAPA-PVK-2( $\left.\mathrm{Q}^{1}\right)$, LLHamide, NSYamide, orcokinin-5, sulfakinin, tachykinin- $1,-3,-4$, and -6 are unidenfied mature peptides.

Both the MALDI-TOF mass spectra of HPLC separation fractions from different developmental stages of silkworm brains and CC-CA extracts of the fifth instar larvae and the MALDI-TOF-TOF fragmentation spectra of the precursor ion at $\mathrm{m} / \mathrm{z}$ were analyzed and identified. A number of $b$-type and y-type ions were labeled (Figures 1-3). Some of them are pGluat of the N-terminal.

\section{Discussion}

Peptides in insects are very important to regulate many physiological activities involved in feeding, ecdysis and metamorphosis, reproduction, energy homeostasis, circadian rhythm, anxiety, seizure, contraction of muscle, learning and memory, and so on [19-22]. Especially, variation of peptidomics at different developmental stages is huge, in which each different stage has characteristic peptides. In this study, we mapped peptides from important neuroendocrine organs, the CC-CA complex, and the brains of silkworms at different stages of growth. The aim of this study was exploring peptidomic composition at different stages because different development stages express specific physiological requirements.

Our results demonstrate that peptidomic variations during different developmental stages are profound in silkworms. In eggs, only few mature peptides were detected; we infer that developmental regulation is operates on a different physiological basis during the egg stage. ACP and AKHs are involved in mobilization of lipids and carbohydrates from fat bodies and ovaries [23]. Besides, allatostatin is involved in inhibition of JH and SGNP in diapause [24]. Compared to larval brains, pupal and adult brains lacked 3 categories (CAPA/CAP2b, NPLP-1, and Leucokinin) and 2 categories (NPLP-1, and Leucokinin), respectively. Of these 3 categories, the CAPA/CAP2b peptides have cardioacceleratory properties and increased heart rate [25-27]. The NPLP-1 was found to play a role in ecdysis behavior in D. melanogaster [ 1 , 28,29 ], and leucokinin is a neurohormone that participates in the regulation of water and ion homeostasis, especially the control of ion transport in the stellate cells of the insect's Malpighian tubules [1].

The peptidomic variation across organs between the brain and the CC-CA complex in larvae was also different. Compared to larval brains, CC-CA complex lacked 3 categories (diapause hormone, SIFamide and leucokinin). The SIFamide has been found to be responsible for courtship. Four SIFamidergic neurons and arborizations play an important function in the neuronal circuitry controlling sexual behavior in Drosophila [28, 29]. In addition, SIFamide may play a role in processing or transmitting tactile, olfactory, and visual stimuli, which is also important for courtship behavior and partner selection [30]. But the function of SIFamide in B. mori and other moths still maintains unclear.

Nowadays, SIFamide, tachykinin (TK), CCAP, CAPAPVK, sulfakinin, and neuropeptide-like precursor 1 (NPLP 1) were predicted by the B. mori genomic database [12]. MIP is another Lepidoptera peptide previously identified from 


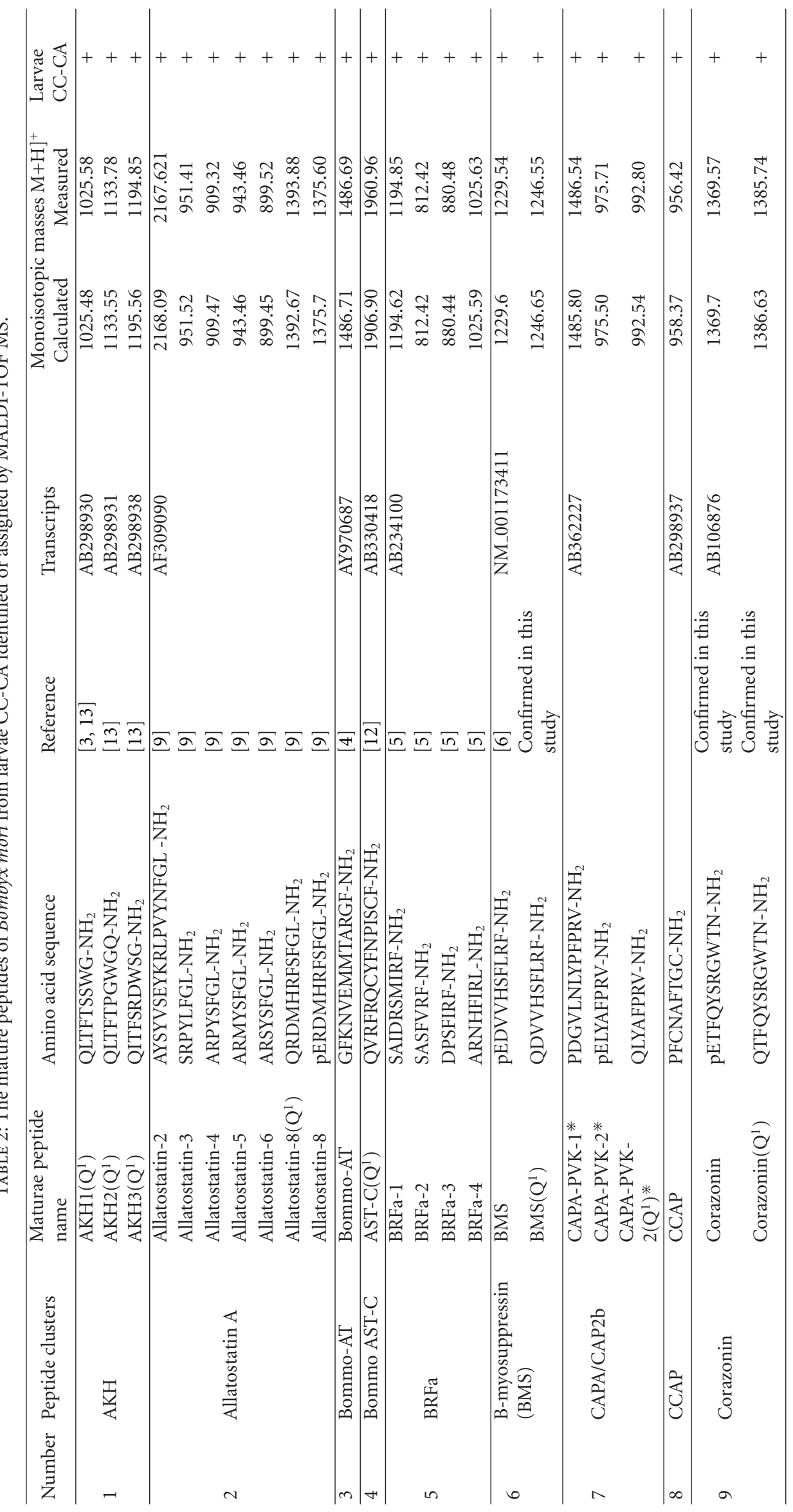




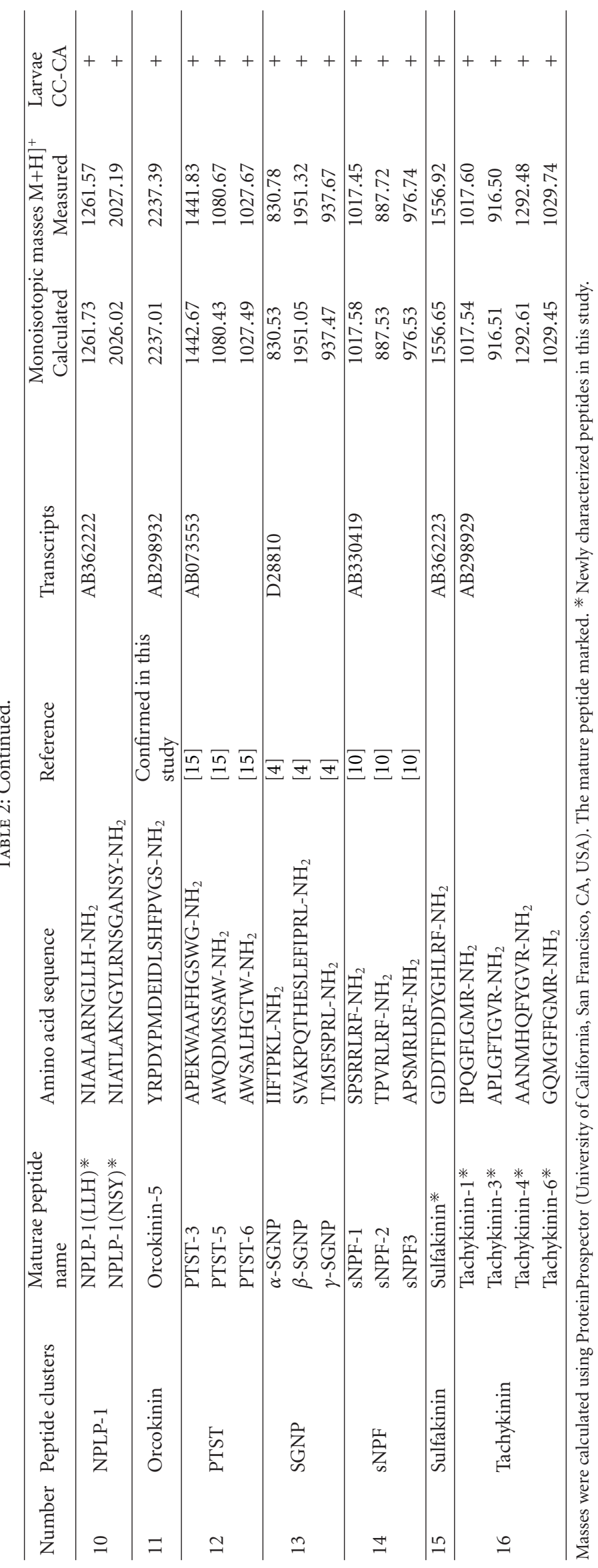




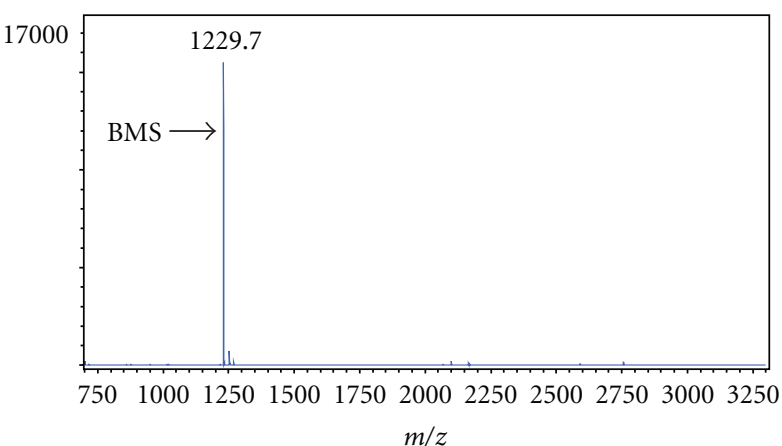

(a) MALDI-TOF-TOF fragmentation spectrum of the precursor ion at $\mathrm{m} / \mathrm{z}$ at 1229.7

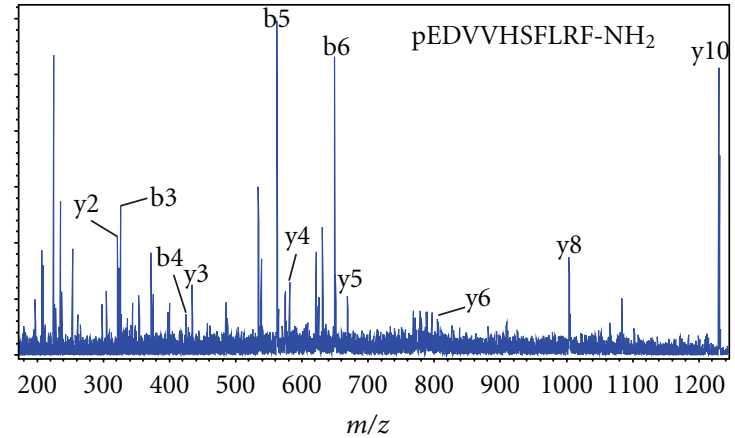

(b) A number of b-type and y-type ions are labeled

FIgURE 2: MALDI-TOF mass spectrum from separate fraction 30 of CC-CA in the fifth instar of B. mori.

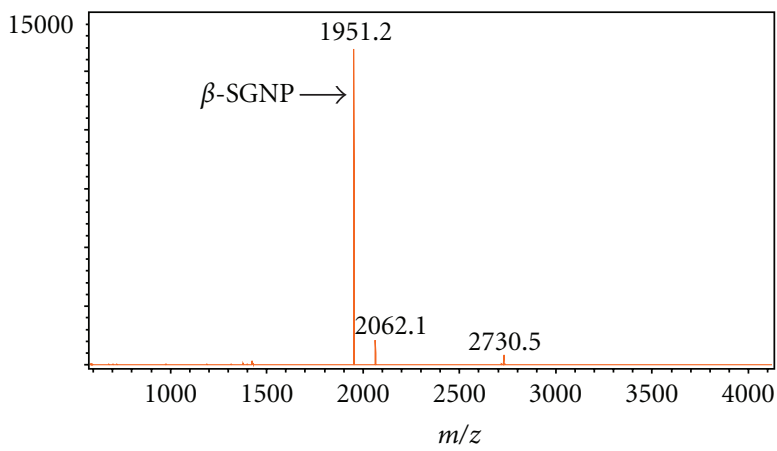

(a) MALDI-TOF-TOF fragmentation spectrum of the precursor ion at $\mathrm{m} / \mathrm{z}$ at 1951.2

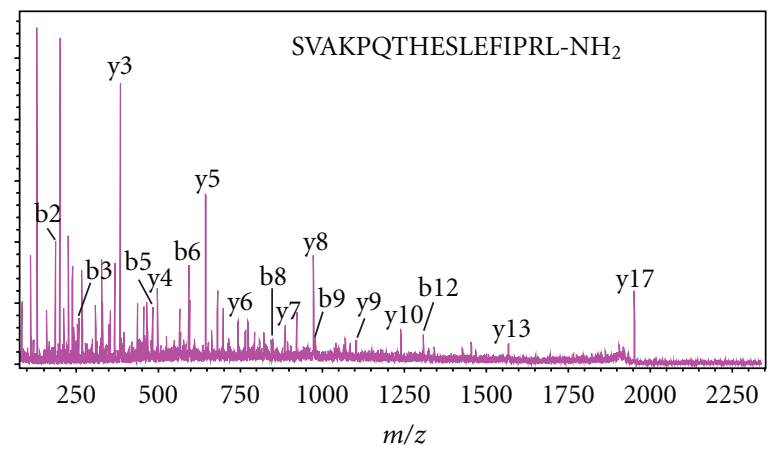

(b) A number of b-type and y-type ions are labeled

FIgUre 3: MALDI-TOF mass spectrum from separate fraction 29 of CC-CA in the fifth instar of B. mori.

Manduca sexta [31]. It was found to have the similar peptide precursor named as B. mori PTST [2-7]. Many neuropeptide precursors undergo a series of enzymatic processes, causing the production of mature, bioactive amidated neuropeptides. Each mature peptide may display a different potential function on the cellular level [32]. The AT/AST has functions in stimulating/inhibiting JH synthesis [33, 34]. The sNPF and tachykinins regulate food intake and consumption but sulfakinin inhibits food intake [35-37]. Corazonin may be the key factor in the formation of colors during the larval stage or reduction of spinning in the pupal stage $[38,39]$. The orcokinins, BRFas, and PTSPs are all involved in the regulation of insect development in ecdysteroid biosynthesis, in which orcokinins have a clear prothoracicotropic activity, in contrast with BRFas [14]. While PTSPs inhibit ecdysteroid biosynthesis in the PG [15]. Again, our results indicate that peptidomics can vary greatly between different organs and developmental stages. The present study adds valuable information to the knowledge of neuropeptidomes.

In this study, all HPLC fractions were collected and analyzed by MALDI-TOF MS, and high-intensity signal peaks consistent with $B$. mori neuropeptides were fragmented by TOF-TOF for peptide identification. However, the apparatus has a limited ability to hit and break ions by TOF-TOF, which is weaker than the ion-trap mass spectrum for some peptides to be not fragmented.

\section{Acknowledgments}

The authors thank Muwang Li (the Sericultural Research Institute, Chinese Academy of Agricultural Sciences) for providing silkworm, and Xinghui Qiu and Mei Li (Institute of Zoology, Chinese Academy of Sciences) for supplying HPLC, and Anthony J. Zera (School of Biological Sciences, University of Nebraska, Lincoln, VE, USA) for revision of the paper. This paper was supported by the National Basic Research Program from Ministry of Science and Technology of China ("973" Program no: 2012CB114100) and the National Science Fund of China (Grant No. 30870339) to Z. W. Zhao.

\section{References}

[1] D. R. Nässel, "Neuropeptides in the nervous system of Drosophila and other insects: multiple roles as neuromodulators and neurohormones," Progress in Neurobiology, vol. 68, no. 1, pp. 1-84, 2002.

[2] Y. J. Hua, J. Ishibashi, H. Saito et al., "Identification of [Arg7] corazonin in the silkworm, Bombyx mori and the cricket, Gryllus bimaculatus, as a factor inducing dark color in an albino strain of the locust, Locusta migratoria," Journal of Insect Physiology, vol. 46, no. 6, pp. 853-859, 2000.

[3] J. Ishibashi, H. Kataoka, H. Nagasawa, A. Isogai, A. Suzuki, and A. Suzuki, "Isolation and identification of adipokinetic 
hormone of the silkworm, Bombyx-Mori," Bioscience Biotechnology and Biochemistry, vol. 56, no. 1, pp. 66-70, 1992.

[4] Y. Sato, M. Oguchi, N. Menjo et al., "Precursor polyprotein for multiple neuropeptides secreted from the suboesophageal ganglion of the silkworm Bombyx mori: Characterization of the cDNA encoding the diapause hormone precursor and identification of additional peptides," Proceedings of the National Academy of Sciences of the United States of America, vol. 90, no. 8, pp. 3251-3255, 1993.

[5] N. Yamanaka, D. Zitnan, Y. J. Kim et al., "Regulation of insect steroid hormone biosynthesis by innervating peptidergic neurons," Proceedings of the National Academy of Sciences of the United States of America, vol. 103, no. 23, pp. 8622-8627, 2006.

[6] N. Yamanaka, Y. J. Hua, A. Mizoguchi et al., "Identification of a novel prothoracicostatic hormone and its receptor in the silkworm Bombyx mori," Journal of Biological Chemistry, vol. 280, no. 15, pp. 14684-14690, 2005.

[7] Y. J. Hua, Y. Tanaka, K. Nakamura, M. Sakakibara, S. Nagata, and H. Kataoka, "Identification of a prothoracicostatic peptide in the larval brain of the silkworm, Bombyx mori," Journal of Biological Chemistry, vol. 274, no. 44, pp. 31169-31173, 1999.

[8] C. Park, J. S. Hwang, S. W. Kang, and B. H. Lee, "Molecular characterization of a cDNA from the silk moth Bombyx mori encoding Manduca sexta allatotropin peptide," Zoological Science, vol. 19, no. 3, pp. 287-292, 2002.

[9] T. Secher, C. Lenz, G. Cazzamali et al., "Molecular cloning of a functional allatostatin gut/brain receptor and an allatostatin preprohormone from the silkworm Bombyx mori," Journal of Biological Chemistry, vol. 276, no. 50, pp. 47052-47060, 2001.

[10] N. Yamanaka, S. Yamamoto, D. Zitnan et al., "Neuropeptide receptor transcriptome reveals unidentified neuroendocrine pathways," PLoS ONE, vol. 3, no. 8, article e3048, 2008.

[11] Q. Xia, Z. Zhou, C. Lu et al., "A draft sequence for the genome of the domesticated silkworm (Bombyx mori)," Science, vol. 306, no. 5703, pp. 1937-1940, 2004.

[12] L. Roller, N. Yamanaka, K. Watanabe et al., "The unique evolution of neuropeptide genes in the silkworm Bombyx mori," Insect Biochemistry and Molecular Biology, vol. 38, no. 12, pp. 1147-1157, 2008.

[13] G. Gäde, H. G. Marco, P. Simek, N. Audsley, K. D. Clark, and R. J. Weaver, "Predicted versus expressed adipokinetic hormones, and other small peptides from the corpus cardiacum-corpus allatum: a case study with beetles and moths," Peptides, vol. 29, no. 7, pp. 1124-1139, 2008.

[14] N. Yamanaka, L. Roller, D. Zitnan et al., "Bombyx orcokinins are brain-gut peptides involved in the neuronal regulation of ecdysteroidogenesis," Journal of Comparative Neurology, vol. 519, no. 2, pp. 238-246, 2011.

[15] N. Yamanaka, Y. J. Hua, L. Roller et al., "Bombyx prothoracicostatic peptides activate the sex peptide receptor to regulate ecdysteroid biosynthesis," Proceedings of the National Academy of Sciences of the United States of America, vol. 107, no. 5, pp. 2060-2065, 2010.

[16] N. Audsley and R. J. Weaver, "Analysis of peptides in the brain and corpora cardiaca-corpora allata of the honey bee, Apis mellifera using MALDI-TOF mass spectrometry," Peptides, vol. 27, no. 3, pp. 512-520, 2006.

[17] N. Audsley and R. J. Weaver, "Identification of neuropeptides from brains of larval Manduca sexta and Lacanobia oleracea using MALDI-TOF mass spectrometry and post-source decay," Peptides, vol. 24, no. 10, pp. 1465-1474, 2003.

[18] K. Mita, M. Morimyo, K. Okano et al., "The construction of an EST database for Bombyx mori and its application,"
Proceedings of the National Academy of Sciences of the United States of America, vol. 100, no. 2, pp. 14121-14126, 2003.

[19] A. Vezzani, G. Sperk, and W. F. Colmers, "Neuropeptide Y: emerging evidence for a functional role in seizure modulation," Trends in Neurosciences, vol. 22, no. 1, pp. 25-30, 1999.

[20] A. Thorsell and M. Heilig, "Diverse functions of neuropeptide Y revealed using genetically modified animals," Neuropeptides, vol. 36, no. 2-3, pp. 182-193, 2002.

[21] H. Herzog, "Neuropeptide Y and energy homeostasis: insights from Y receptor knockout models," European Journal of Pharmacology, vol. 480, no. 1-3, pp. 21-29, 2003.

[22] T. Pedrazzini, F. Pralong, and E. Grouzmann, "Neuropeptide Y: the universal soldier," Cellular and Molecular Life Sciences, vol. 60, no. 2, pp. 350-377, 2003.

[23] J. V. Stone, W. Mordue, K. E. Batley, and H. R. Morris, "Structure of locust adipokinetic hormone, a neurohormone that regulates lipid utilisation during flight," Nature, vol. 263, no. 5574, pp. 207-211, 1976.

[24] A. P. Woodhead, B. Stay, S. L. Seidel, M. A. Khan, and S. S. Tobe, "Primary structure of four allatostatins: neuropeptide inhibitors of juvenile hormone synthesis.," Proceedings of the National Academy of Sciences of the United States of America, vol. 86, no. 15, pp. 5997-5601, 1989.

[25] C. C. Cheung, P. K. Loi, A. W. Sylwester, T. D. Lee, and N. J. Tublitz, "Primary structure of a cardioactive neuropeptide from the tobacco hawkmoth, Manduca sexta," FEBS Letters, vol. 313, no. 2, pp. 165-168, 1992.

[26] G. R. Huesmann, C. C. Cheung, P. K. Loi, T. D. Lee, K. M. Swiderek, and N. J. Tublitz, "Amino acid sequence of CAP $(2 b)$, an insect cardioacceleratory peptide from the tobacco hawkmoth Manduca sexta," FEBS Letters, vol. 371, no. 3, pp. 311314, 1995.

[27] H. K. Lehman, C. M. Murgiuc, T. A. Miller, T. D. Lee, and J. G. Hildebrand, "Crustacean cardioactive peptide in the sphinx moth, Manduca sexta," Peptides, vol. 14, no. 4, pp. 735-741, 1993.

[28] G. Baggerman, A. Cerstiaens, A. De Loof, and L. Schoofs, "Peptidomics of the larval Drosophila melanogaster central nervous system," Journal of Biological Chemistry, vol. 277, no. 43, pp. 40368-40374, 2002.

[29] G. Baggerman, K. Boonen, P. Verleyen, A. De Loof, and L. Schoofs, "Peptidomic analysis of the larval Drosophila melanogaster central nervous system by two-dimensional capillary liquid chromatography quadrupole time-of-flight mass spectrometry," Journal of Mass Spectrometry, vol. 40, no. 2, pp. 250 260, 2005.

[30] P. Verleyen, J. Huybrechts, G. Baggerman, A. Van Lommel, A. De Loof, and L. Schoofs, "SIFamide is a highly conserved neuropeptide: a comparative study in different insect species," Biochemical and Biophysical Research Communications, vol. 320, no. 2, pp. 334-341, 2004.

[31] M. B. Blackburn, H. Jaffe, J. Kochansky, and A. K. Raina, "Identification of four additional myoinhibitory peptides (MIPs) from the ventral nerve cord of Manduca sexta," Archives of Insect Biochemistry and Physiology, vol. 48, no. 3, pp. 121-128, 2001.

[32] P. McVeigh, M. J. Kimber, E. Novozhilova, and T. A. Day, "Neuropeptide signalling systems in flatworms," Parasitology, vol. 131, Supplement 1, pp. S41-S55, 2005.

[33] H. Kataoka, A. Toschi, J. P. Li, R. L. Carney, D. A. Schooley, and S. J. Kramer, "Identification of an allatotropin from adult Manduca sexta," Science, vol. 243, no. 4897, pp. 1481-1483, 1989. 
[34] S. J. Kramer, A. Toschi, C. A. Miller et al., "Identification of an allatostatin from the tobacco hornworm Manduca sexta," Proceedings of the National Academy of Sciences of the United States of America, vol. 88, no. 21, pp. 9458-9462, 1991.

[35] K. S. Lee, K. H. You, J. K. Choo, Y. M. Han, and K. Yu, "Drosophila short neuropeptide F regulates food intake and body size," Journal of Biological Chemistry, vol. 279, no. 49, pp. 50781-50789, 2004.

[36] N. Pascual, J. L. Maestro, C. Chiva, D. Andreu, and X. Bellés, "Identification of a tachykinin-related peptide with orexigenic properties in the German cockroach," Peptides, vol. 29, no. 3, pp. 386-392, 2008.

[37] Z. Wei, G. Baggerman, R. JN et al., "Sulfakinins reduce food intake in the desert locust, Schistocerca gregaria," Journal of Insect Physiology, vol. 46, no. 9, pp. 1259-1265, 2000.

[38] Y. Tanaka, Y. J. Hua, L. Roller, and S. Tanaka, "Corazonin reduces the spinning rate in the silkworm, Bombyx mori," Journal of Insect Physiology, vol. 48, no. 7, pp. 707-714, 2002.

[39] A. I. Tawfik, S. Tanaka, A. De Loof et al., "Identification of the gregarization-associated dark-pigmentotropin in locusts through an albino mutant," Proceedings of the National Academy of Sciences of the United States of America, vol. 96, no. 12, pp. 7083-7087, 1999. 

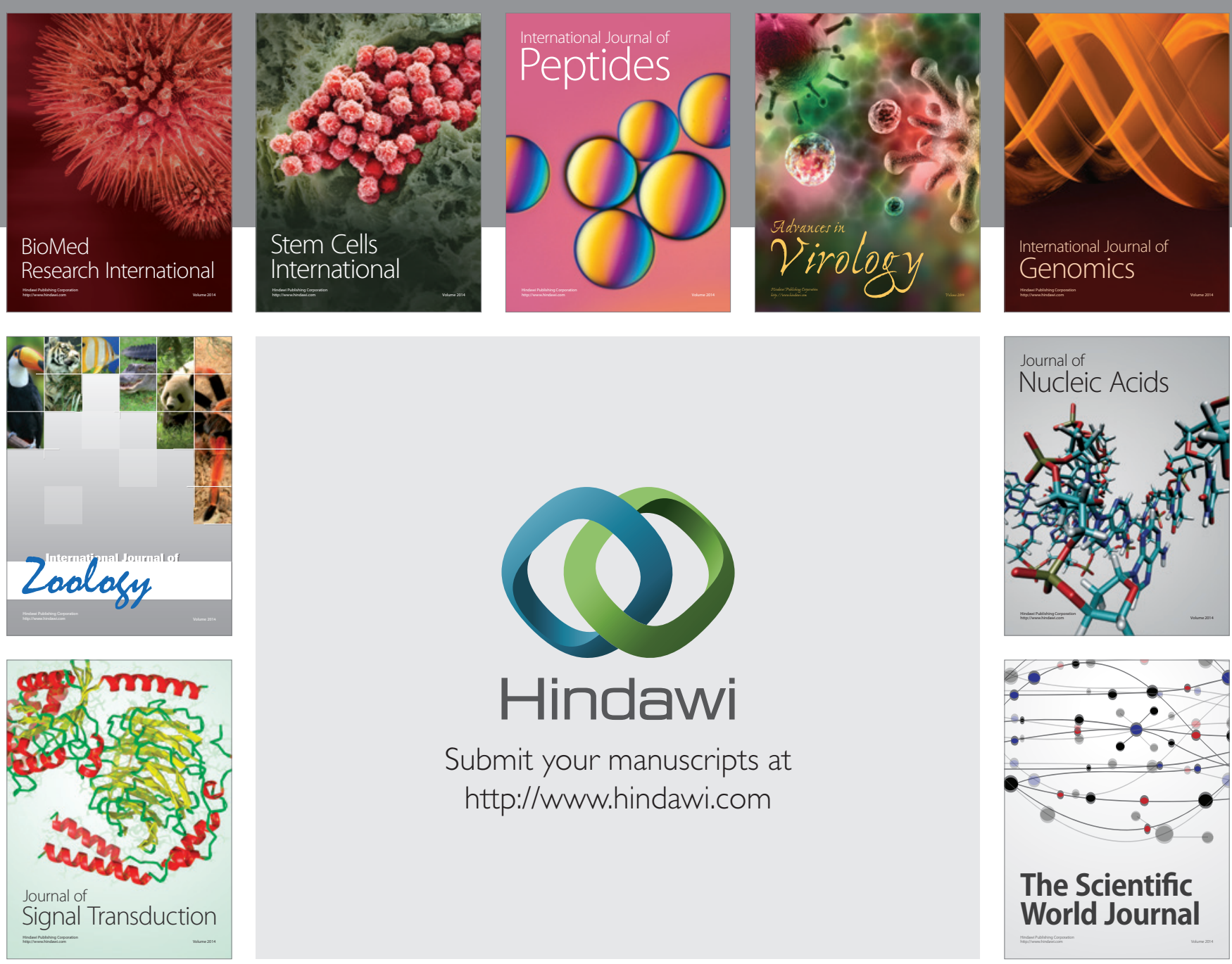

Submit your manuscripts at

http://www.hindawi.com
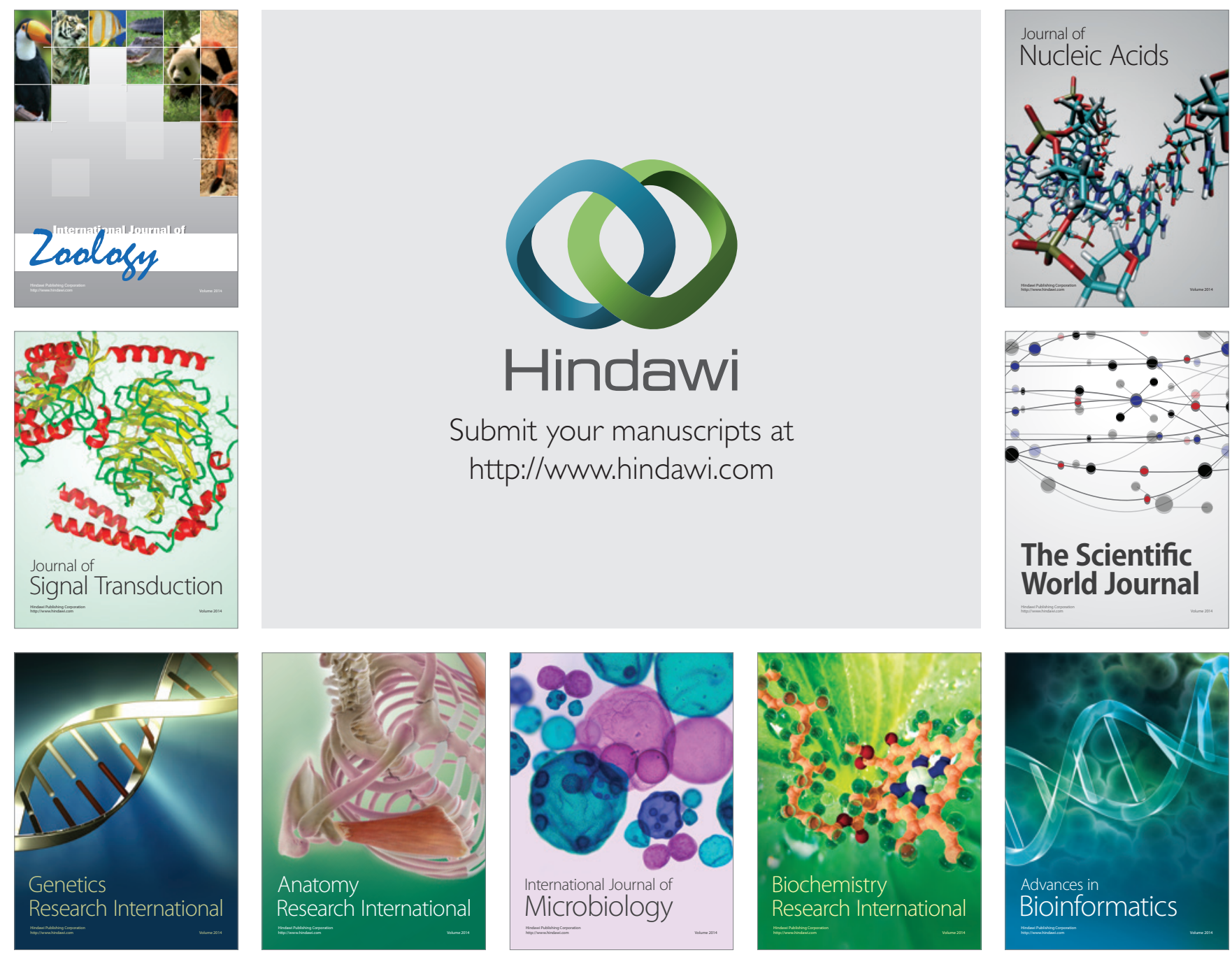

The Scientific World Journal
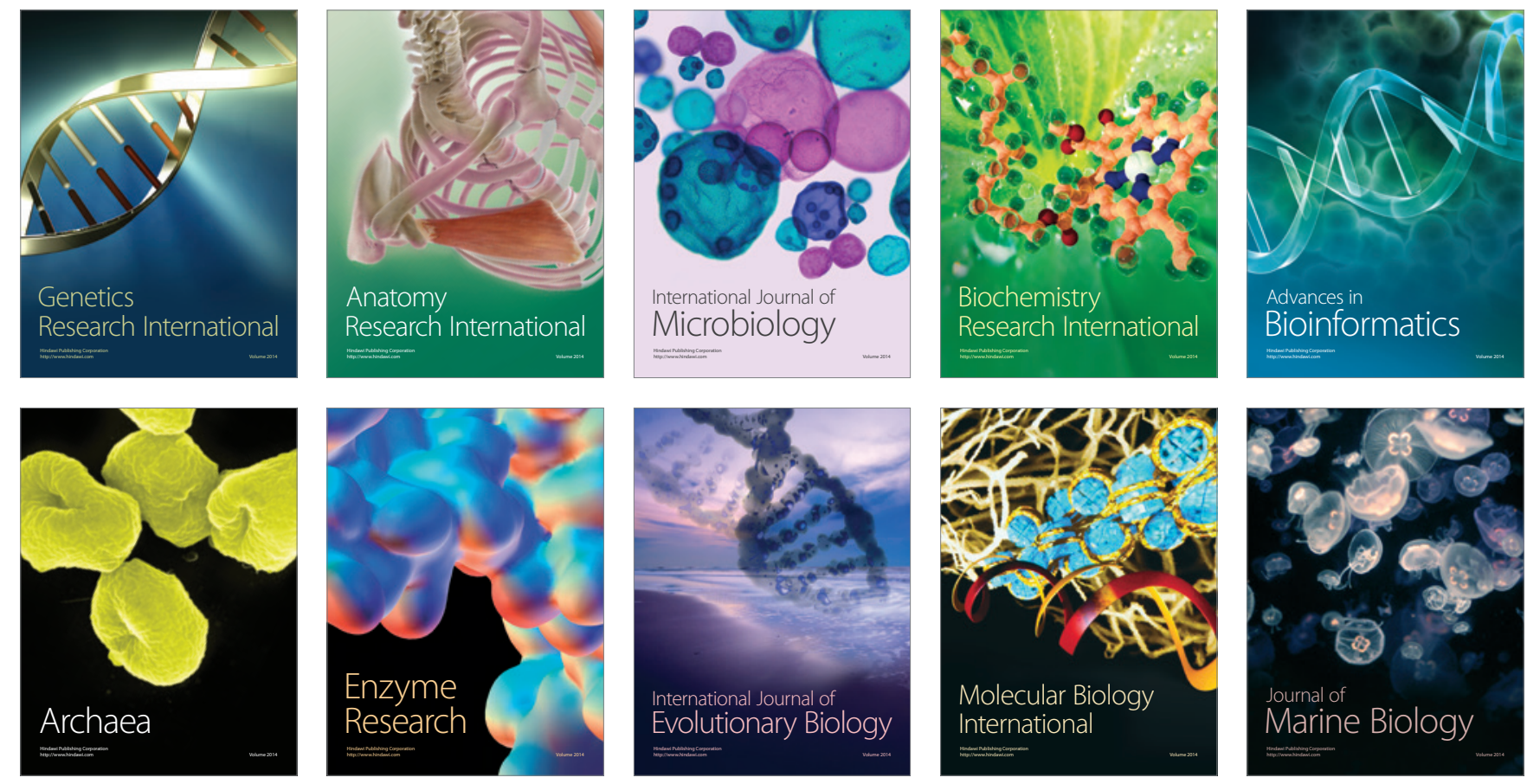